Analysing students' cognitive engagement in e-learning discussion forums through content analysis

Si Na Kew

Zaidatun Tasir

Universiti Teknologi Malaysia, Malaysia

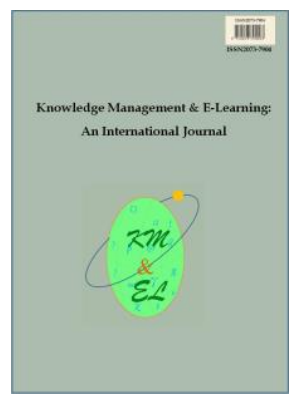

Knowledge Management \& E-Learning: An International Journal (KM\&EL) ISSN 2073-7904

Recommended citation:

Kew, S. N., \& Tasir, Z. (2021). Analysing students' cognitive engagement in e-learning discussion forums through content analysis. Knowledge Management \& E-Learning, 13(1), 39-57. https://doi.org/10.34105/j.kmel.2021.13.003 


\title{
Analysing students' cognitive engagement in e-learning discussion forums through content analysis
}

\author{
Si Na Kew* \\ Faculty of Social Sciences and Humanities \\ Universiti Teknologi Malaysia, Malaysia \\ E-mail: snkew@utm.my
}

\section{Zaidatun Tasir}

Faculty of Social Sciences and Humanities

Universiti Teknologi Malaysia, Malaysia

E-mail: p-zaida@utm.my

*Corresponding author

\begin{abstract}
Discussion forums provide students with accessible platforms for group discussions in e-learning environments. They also help lecturers to track and check student discussions. To improve student learning, it is important for lecturers to identify students' cognitive engagement in discussion forums. Therefore, this study aims to investigate students' cognitive engagement in elearning through content analysis of forum posts. A total of 267 forum posts created by students during one semester were collected for analysis. Inferential statistics were applied to explore the relationship between students' cognitive engagement and their gender and the number of posts in forums. The results revealed that about half of the students gave their posts without any explanations, which reflected a low level of cognitive engagement. A large number of posts made little contribution to a high level of cognitive engagement. The results also showed no relationship between gender and the level of cognitive engagement. The limitations and implications of this study are also discussed.
\end{abstract}

Keywords: Cognitive engagement; Forum discussion; e-Learning; Content analysis; Learning analytics

Biographical notes: Dr. Si Na Kew is a senior lecturer at Language Academy, Faculty of Social Sciences and Humanities, Universiti Teknologi Malaysia, Malaysia. She received a bachelor in TESL at Universiti Teknologi Malaysia and completed her $\mathrm{PhD}$ studies in educational technology at Universiti Teknologi Malaysia. Her research interests are educational technology, online teaching and learning, learning analytics (LA), teaching English as a second language (TESL), technology enhanced language learning (TELL), computer assisted language learning (CALL), etc. She is currently one of the affiliates of the Young Scientist Network Academy of Sciences Malaysia (YSN-ASM).

Dr. Zaidatun Tasir is a Professor at School of Education, Faculty of Social Sciences \& Humanities, Universiti Teknologi Malaysia. She is currently the Dean of the Faculty of Social Sciences and Humanities, UTM. She completed her bachelor, Master's and PhD degrees in 1995, 1998, and 2003, respectively. Her research interests include educational technology, computers and education, learning analytics, and education 4.0. She has published more than 100 research 
articles related to the mentioned areas in journals such as Computers \& Education, Educational Technology Research and Development, Journal of Educational Technology \& Society, Journal of Educational Research Computing, among others. Presently, she is an Editor-in-Chief of Innovative Teaching and Learning Journal (ITLJ) and The International Journal of Education and Learning (IJELE).

\section{Introduction}

As technology developments increase, many universities have adopted e-learning to improve their teaching and learning processes. This has led to a shift from traditional classroom education to online learning, which has influenced educational practices (Hong et al., 2017). For instance, more online activities are designed for students, such as discussion forums to increase student participation in e-learning. In fact, much research has been conducted that shows the positive impact of participation by students in their elearning activities (Kim, 2013). However, one of the challenges in the e-learning environment is that educators are unable to observe students' learning participation through being present in the classroom and have less direct face-to-face interaction with students who participate in e-learning (Luo et al., 2017) and, in particular, in discussion forum activity. To solve this issue, the data generated by students when interacting with e-learning activities, such as the number of posts and replies, can be tracked and analysed to discover the students' learning performances in e-learning. This data can assist instructors in understanding what has happened in e-learning. This scenario has led to the emergence of learning analytics, which is growing rapidly (Lee, Cheung, \& Kwok, 2020; West et al., 2016), with the aim of optimising students' learning experiences through collecting the students' data and analysing the data using different analytical methods to establish the students' learning behaviours. It is also used to discover the hidden information about students (Mattingly et al., 2012) and predict the learning outcomes (Yin \& Hwang, 2018).

Additionally, as e-learning has become more pervasive, researchers have begun to analyse the data generated by students in order to explore how to make e-learning more effective and to help to motivate students to achieve their full potential in e-learning, especially in discussion forums. Boyle and Nicol (2003) highlighted that students acquire in-depth knowledge by being involved in discussions, while enquiring, analysing, and elaborating leads to more active and engaged learning among students (Bangert, 2004). In this regard, some scholars have explored the issue of cognitive engagement in the context of technology use in e-learning (Bai, 2003), such as whether students have read, understood, and replied to the messages in discussion forums. Moreover, the key to the effective implementation of e-learning courses is how the students become engaged by the content (Kigundu, 2014) and whether they have engaged cognitively in the discussion forum. Spanjers (2007) pinpointed that cognitive engagement is the predictor of learning achievement, and thus, it plays an important role. Correspondingly, cognitive engagement is connected to the mental efforts of students who are able to show a high level of understanding and improved learning (Hayati, Idrissi, \& Bennani, 2017).

Generally, student engagement is categorized into three dimensions: emotional (the way they feel), cognitive (the way they think), and behavioural (the way they act) (Moreira, Cunha, \& Inman, 2020). According to Wang et al. (2015), emotional engagement is related to students' interest in and feelings about the course, while behavioural engagement is about their commitment to following the rules set by the 
instructors delivering the course. Meanwhile, cognitive engagement is presented by students when they make a mental effort to engage with the learning resources in the course. These dimensions play different roles in e-learning. However, according to Appleton et al. (2006), less research has focused on cognitive engagement than on behavioural engagement in e-learning. This conclusion was confirmed by Kim (2013), who pointed out that the research has commonly investigated the behavioural engagement in e-learning and reported that the number of interactions increases when the number of participants increases, but the relationship between the number of interactions and the qualitative aspects of interactivity remains ambiguous. Furthermore, Wysocki (2007) emphasised the necessity of assessing the quality of online learning, especially in discussion forums. One of the ways to make such an assessment is to examine the students' cognitive engagement. Shukor et al. (2014) agreed and also urged that there was a need to evaluate the students' cognitive engagement in discussion forums to enhance the quality of online learning, as cognitive engagement in online discussion forums is vital to make sure that students make a high mental effort (Oh \& Kim, 2016).

Furthermore, the role of students' profile might affect their learning performance in e-learning. As Casimiro (2016) pointed out, gender could influence the participation and interaction of students in online learning. In other words, students' gender might be associated with their cognitive engagement level in e-learning. Also, the amount of participation and interaction, such as the total number of posts and views (Hayati et al., 2017), might influence the students' cognitive engagement in online learning, as Wang et al. (2015) reported that there is a link between the quality and the quantity of participation and interaction in the discussion forum and the learning performance.

Therefore, this study examined students' cognitive engagement level in e-learning discussion forums through content analysis of discussion posts. The research questions (RQs) of the study were as follows been implemented.

RQ1: To what extent are students cognitively engaged in discussion forums in elearning?

RQ2: What is the relationship between the students' cognitive engagement level and their gender?

RQ3: What is the relationship between the students' cognitive engagement level and the number of posts they make in discussion forums?

\section{Literature review}

\subsection{Discussion forums in e-learning}

A discussion forum is considered a tool used by participants to discuss and interact without place and time restrictions (Goggins \& Xing, 2016), and it is regarded as a useful tool to develop the cognitive dimension. In this respect, discussion forums are widely used by educators in e-learning as a way for students to interact, particularly for those who are shy or demotivated and who have difficulty interacting during e-learning (Nor et al., 2010; Kew, Petsangsri, \& Tasir, 2020). In addition, in discussion forums, participants can choose to reply to current topics or are free to create new topics, and all posts in the forum are recorded in chronological order (Gao et al., 2013). This can make it convenient for educators to access the posts, and the participants are able to reflect at any time on the overall topic and on what they have posted (Salmon, 2011). Moreover, researchers can 
analyse log data in e-learning to examine engagement, which has different types, such as behavioural, cognitive, and emotional engagement, which can be used to understand the quality of learning activities and environment. Behavioural engagement is regarded as the participation in course activities (Archambault et al., 2009), and cognitive engagement is the mental effort paid to understand the complex idea (Harris, 2008), while emotional engagement indicates students' positive responses to and feelings about their learning (Gibbs \& Poskitt, 2010).

Other than that, e-learning discussion forums enable participants to make posts easily, but a research review conducted by Hammond (2005) reported that interaction was frequently measured in terms of frequency rather than in terms of quality. In other words, it is difficult for educators to understand the quality of discussion posts in elearning. Mazzolini and Maddison (2003) also added that the number of posts cannot be used as an indicator of the quality of a discussion. This view was echoed by Lucas, Gunawardena, and Moreira (2014) in a study about increasing attention in the assessment of online discussion, which in turn has attracted the interest of researchers in using different methods to examine the online discussion quality. Therefore, more research into measuring the quality of interactions, in terms of the students' cognitive engagement, should be conducted to measure how much mental effort is made by participants when engaging in discussions.

\subsection{Cognitive engagement}

Newmann et al. (1992) define cognitive engagement as "the student's psychological investment in and effort directed toward learning, understanding, or mastering the knowledge, skills, or crafts that academic work is intended to promote" (p. 12), while Zhu (2006) explained cognitive engagement as "attention to related readings and effort in analysing and synthesizing readings demonstrated in discussion messages" (p. 454), and this is the definition used in this study. According to Chapman (2003), cognitive engagement is the extent to which students try in intellectual tasks or how much mental effort they use in the learning activities given, for instance, the effort students put into completing a task by using knowledge and cognitive strategy. In education, writing can not only make students more engaged because it 'forces' them to think before they write, but it can also stimulate behavioural and cognitive changes that can enable the reconstruction of knowledge (Mason, 2001). Hence, this study investigates the posts written by the students in discussion forums.

In addition, according to Brown (2010), different levels of complication may be identified in students' cognitive performances, namely, low level and high level. For the low level, the students perform their tasks through cognitively low-level and simple activities, including producing previously acquired truths or meanings. Compared to the high level, the low level requires only limited cognitive demand to complete the tasks. In contrast, for a high level of cognitive complexity, the given activities involve a more challenging and higher cognitive demand, construction, and sustained reflection, resulting in a high level of engagement. These activities need students to discover and to know the nature of concepts and developments and the connections between them to achieve a higher level of cognitive engagement. Based on the high and low levels of students' cognitive complexity, instructors and educators can reassess their teaching and learning practices and design the learning materials in a more effective way.

Apart from that, students' engagement might be influenced by different factors. The factors such as profile, including gender, experience in online learning, etc. may affect or correlate with the participation level (Cisel, 2014) and cognitive engagement 
level in forum discussion activity. Canchola González, and Glasserman-Morales (2020) pointed out that features of the students' profile, such as gender and age, could be the factors that contribute to the students' engagement and retention level in an online course. Wysocki (2007) also examined whether gender data could affect cognitive engagement. Additionally, the relationships of engagement with learning performance were affected by cultural value, gender, etc. (Lei, Cui, \& Zhou, 2018). However, Zyngier (2007) claimed that some studies do not take into account factors such as gender, ethnic, economic status and so on when investigating engagement. The study conducted by Casimiro (2016) also shows that it was still unclear in the interactions if culture or gender are still an issue in an online class. Thus, more studies should be conducted to investigate the relationship between engagement and gender. Apart from that, Wang et al. (2015) reported that there is a vital link between the quality and quantity of interaction and participation in the discussion forum, whereby the students' total number of postings were obtained from the $\log$ file of the forum and used to support the quantitative data (Nor et al., 2010). Thus, it is also necessary to find more evidence about the relationship between cognitive engagement and the number of posts.

\subsection{Content analysis of discussion posts}

In content analysis, which is regarded as a common way to analyse individual contributions to discussion forums in e-learning, the forum transcripts are coded by reference to a coding scheme in order to obtain evidence relating to knowledge transfer and the learning process (De Wever et al., 2006). This method is used to assist in understanding the qualitative aspects of participation (Kim, 2013) and in measuring the students' cognitive engagement in e-learning (McLoughlin \& Luca, 2000; Shukor et al., 2014). Nonetheless, some studies have used other analytical methods to measure cognitive engagement. For example, Hayati et al. (2017) used text mining to propose a predictive system for students' cognitive engagement by analysing their participation in online discussion forums. Furthermore, Moore et al. (2019) examined cognitive processing in discussion forums by using automatic text analysis. However, this study used the content analysis method to examine the level of students' cognitive engagement in e-learning.

\subsection{Related work on cognitive engagement}

Stoney and Oliver (1999) divided cognitive engagement into higher and lower order thinking and proposed that higher order thinking students spent much more time and took part more enthusiastically in academic activities. This led them to achieve higher levels of learning compared to those whose order of thinking was low. In fact, lower-order thinking needs low cognitive engagement in operational activities and, to develop higherorder thinking skills, it is necessary to be able to reflect on learning experiences and to integrate new knowledge with pre-existing knowledge. Predicting and imposing multiple perspectives are examples of higher-order thinking activities that require high cognitive engagement. Furthermore, McLoughlin and Luca (2000) investigated students' cognitive engagement and higher order thinking in online learning settings by applying the content analysis method. The findings showed that most of the discussion forum messages were in the phase of cognitive interaction and the sharing and comparing of information, such as the elaboration of existing knowledge only.

Van der Meijden (2005) examined cognitive engagement from the perspective of social knowledge construction. There are two categories: a high or a low level of 
cognitive engagement. Students with a low level of cognitive engagement did not elaborate on their statements when constructing knowledge, whereas students with a high cognitive engagement level did elaborate on their statements and provided more explanations. On the other hand, Helme and Clarke (2001) observed different patterns of students' cognitive engagement. Similarly, Zhu (2006) explored cognitive engagement in online learning and, by analysing discussion transcripts, found that students' levels of cognitive engagement varied from high to low. This study highlights that transcripts are an effective tool for noting specific behaviours that would be indicative of participants who could be categorised as cognitively engaged. Li and Baker (2018), on the other hand, measured behavioural and cognitive engagement in MOOCs, and the result showed that the same engagement measure may be oppositely associated with achievement for different groups.

Furthermore, Wysocki's (2007) study found that prior online learning experience did not influence cognitive engagement. Meanwhile, Sedaghat et al. (2011) carried out research into the effect of motivational factors on cognitive engagement and academic achievement. In addition, another significant study was conducted by Shukor et al. (2014). They examined students' cognitive engagement in an online learning environment and generated a model that can predict future cognitive engagement in an online learning environment. Their findings indicated that the students' cognitive engagement levels were much lower, and the mean for low-level cognitive contributions was higher than for high-level cognitive contributions.

\section{Method}

\subsection{Research design}

A quantitative methodology was adopted in this study to identify the students' cognitive engagement level in e-learning and to discover how much effort had been made and how much attention paid by students in analysing and synthesising the reading of discussion messages. A total of four different topics, all related to the teaching subject for the discussion, were given by the instructor for discussion in e-learning at different times throughout the 17-week semester. There was no moderator in the discussion.

\subsection{Sample}

A random clustering sampling technique was applied. A whole class of Year One undergraduate Teaching English as a Second Language (TESL) students, who were taking the educational technology subject at a university in Malaysia and who had voluntarily completed the forum discussion tasks given in e-learning for one semester, was chosen. The total number of students was 23 . These students knew how to use elearning and had mastered computer skills. The students were divided into different groups to carry out their group discussions in e-learning, with each group comprising three to four students. Consent was also obtained from the students and the instructor for use of their in this study.

\subsection{Instrument}

In order to measure the students' cognitive engagement level, e-learning discussion forums were used to collect the data generated by students in e-learning, such as written 
messages and posts in their discussion forums. Then, the discussion forum scripts and server log files were collected and analysed using content analysis.

\subsection{Data analysis}

The analytical method used in this study was content analysis with reference to the social knowledge construction coding scheme (Van der Meijden, 2005) to analyse the online discussion scripts of the students. As shown in Table 1, the coding scheme has the categories of high-level contributions (with a mark of *), low level contributions, affective, regulative, and rest. Van der Meijden categorises this coding scheme as cognitive (asking questions, giving answers, and giving information), affective, regulative and rest. However, affective, regulative, and rest are not included when calculating the cognitive engagement level of students in this study according to Table 2 because these categories do not involve any cognitive element.

In terms of asking questions, the data consists of asking questions with/without explanation and asking for agreement (e.g., CHV1, *CHV2 and CHVER) while, for giving answers, it consists of answering with/without explanation (e.g., CHG1 and ${ }^{*} \mathrm{CHG} 2$ ). In terms of giving information, it comprises giving information with/without elaboration, referring to earlier information, evaluating the content, accepting the statement with/without elaboration, and rejecting the statement with/without elaboration (e.g., CI 1, *CI2, CIT, CIE, ACCEPT-, * ACCEPT+, REJECT- and *REJECT+). These coding schemes are used to determine whether a student is at a high cognitive engagement level, a low cognitive engagement level, or a high-low cognitive engagement level according to Table 2. This will be explained in more detail in the following section.

Table 1

Social knowledge construction coding scheme (Van Der Meijden, 2005)

\begin{tabular}{|c|c|c|}
\hline Category & & Example \\
\hline \multicolumn{3}{|c|}{ Cognitive: Asking Questions } \\
\hline CHV 1 & $\begin{array}{l}\text { Asking questions that do not } \\
\text { require an explanation (facts or } \\
\text { simple questions) }\end{array}$ & $\begin{array}{l}\text { Has the problem been solved? } \\
\text { How many types of images are they? }\end{array}$ \\
\hline *CHV 2 & $\begin{array}{l}\text { Asking questions that require an } \\
\text { explanation (comprehension or } \\
\text { elaboration) }\end{array}$ & $\begin{array}{l}\text { You have explained all the units for developing } \\
\text { the website, but which one is preferable and } \\
\text { why? } \\
\text { Do you have any idea on solving the problem? } \\
\text { Can we do anything to fix this? }\end{array}$ \\
\hline CHVER & $\begin{array}{l}\text { Verification or asking for } \\
\text { agreement }\end{array}$ & $\begin{array}{l}\text { Is it true? } \\
\text { Am I explaining correctly? } \\
\text { Correctly? }\end{array}$ \\
\hline \multicolumn{3}{|c|}{ Cognitive: Giving Answers } \\
\hline CHG 1 & Answering without explanation & $\begin{array}{l}\text { There are } 3 \text { types of images. } \\
\text { The problem has been solved. } \\
\text {.jpeg is different from .png image. }\end{array}$ \\
\hline *CHG 2 & $\begin{array}{l}\text { Answering with explanation } \\
\text { (using arguments or by asking a } \\
\text { counter-question) }\end{array}$ & $\begin{array}{l}\text { It means that not all computer resolution is the } \\
\text { same because .. } \\
\text { The information shows that .. }\end{array}$ \\
\hline
\end{tabular}




\section{Cognitive: Giving Information \\ CI 1 Giving information (an idea or thought) without elaboration \\ ${ }^{*}$ CI 2 Giving information (an idea or thought) with elaboration}

CIT

CIE Evaluating the content

(summarizing/concluding)

ACCEPT- Accepting contribution of another participant without elaboration

*ACCEPT+ Accepting contribution of another participant with elaboration

NACCEPT- $\quad$ Not accepting contribution of another participant without elaboration

*NACCEPT + Not accepting contribution of another participant with elaboration

\section{Affective}

A

Regulative

$\mathrm{RV}$

RINS

Rest

AND

GREE
Positive, neutral or negative emotional reaction to another participant or regarding the task

Planning, monitoring, and evaluation of the task or group process

Instructing: One participant instructs another participant

Non-task-related remarks, unfinished sentences, or interactions that do not fall into any other category

Greetings to indicate the presence or absence of a person
I paste the information from the internet as presented below ..

From what I see, both images look the same.

I guess the alternative way to solve this is by .. From the example that I obtained from the internet below, they say that ..

Some of the discussion said so because ..

We often have the same problem..

This problem has occurred to me before ..

Based on Aishah's explanation ..

So, the verdict is..

We can conclude that..

I agree.

You might be true.

I agree with you because..

because..

Aishah is right because ..

I don't think that is the cause of the problem.

I don't think that is right.

That might not be the problem because ..

I disagree with you because ..

Thank you for the explanation.

Good job everyone!

I am confused now ..

Why don't we first do this ..

Have you finish with that problem?

We should do this ..

Why don't Ahmad do this part?

Azmi, I think you should handle this.

What are you doing this Saturday?

The internet is slow..

\section{Assalamualaikum}

$\mathrm{Hi}$

Good morning

That's all, thank you

Note. * indicates high-level cognitive engagement

In this study, the unit of meaning was used as the unit of analysis. The coding session conducted by this research resulted in an inter-rater reliability of $87.93 \%$ between the expert and the researcher, and the Kappa value was 0.951, which is reliable (Landis \& 
Koch, 1977). The researcher then started to code the scripts in the discussion forums generated by students using the content analysis method. The total number of posts created by the students from the one course was 267 messages with 293 segments. The students' level of cognitive engagement was then measured by comparing the percentage of low-level cognitive contributions with the percentage of high-level cognitive contributions, as shown in Table 2.

Table 2

Group identification based on knowledge construction level

\begin{tabular}{lc}
\hline \multicolumn{1}{c}{ Details } & \multicolumn{1}{c}{ Group Type } \\
\hline $\begin{array}{l}\text { \#High-level cognitive contribution }>\text { \#Low-level } \\
\text { cognitive contribution }\end{array}$ & High cognitive engagement level \\
\#High-level cognitive contribution = \#Low-level & High-low cognitive engagement level \\
$\begin{array}{l}\text { cognitive contribution } \\
\text { \#High-level cognitive contribution }<\text { \#Low-level } \\
\text { cognitive contribution }\end{array}$ & Low cognitive engagement level \\
\hline
\end{tabular}

Moreover, the Statistical Package for the Social Sciences (SPSS) was used to investigate the relationship of the students' cognitive engagement with their gender and their number of posts. To be more specific, according to the categories of Van der Meijden (2005), the cognitive engagement level of the students was calculated to be classified into a high (H), high-low (HL) or low (L) level of cognitive engagement (cited in Shukor et al., 2014). Shukor et al. (2014) also used this method to compare the percentage of their high-level cognitive contributions (with a mark of *) with the lowlevel cognitive contributions in order to identify the cognitive engagement level. Thus, this study aims to use the same method to find out the cognitive engagement.

\section{Results}

This section reports the results of the study.

\subsection{Students' cognitive engagement level}

Table 3 shows that the students invest different cognitive engagement levels in forum discussions.

Table 3

Number of students based on knowledge construction levels

\begin{tabular}{lccc}
\hline No. & Cognitive Engagement Level & Number of Students & Percentage \\
\hline 1 & High & 9 & $39 \%$ \\
2 & High Low & 2 & $9 \%$ \\
3 & Low & 12 & $52 \%$ \\
Total & & 23 & 100 \\
\hline
\end{tabular}

From Table 3, the results show that $52 \%$ of the students belong to the low cognitive engagement level, which means that these students used less cognitive demand 
when they wrote their posts in the discussion forum. Conversely, there are nine students (39\%) with a high cognitive engagement level and only two students (9\%) possessed a high-low cognitive engagement level. Furthermore, it is vital to analyse the students' overall interaction patterns in forum discussions based on the coding scheme, which can illustrate the thinking activities used by students to process and understand the content of messages during their discussions and interactions with others. In this respect, Table 4 shows that high-level and low-level contributions, affective, regulative and rest are found in discussion forums. This can provide a richer picture of the message types posted by students.

Table 4

Cognitive contributions and affective found in discussion forum

\begin{tabular}{|c|c|c|}
\hline Cognitive Engagement & Total, $\mathrm{T}(\mathrm{n}=293)$ & Percentage, $\%$ \\
\hline (i) Cognitive contributions & & 88.40 \\
\hline CHV 1 & 15 & 5.12 \\
\hline *CHV 2 & 10 & 3.41 \\
\hline CHVER & 7 & 2.39 \\
\hline CHG 1 & 19 & 6.48 \\
\hline *CHG 2 & 55 & 18.77 \\
\hline CI 1 & 64 & 21.84 \\
\hline *CI 2 & 20 & 6.83 \\
\hline CIT & 6 & 2.05 \\
\hline CIE & 6 & 2.05 \\
\hline ACCEPT- & 17 & 5.80 \\
\hline *ACCEPT+ & 37 & 12.63 \\
\hline NACCEPT- & 0 & 0.00 \\
\hline *NACCEPT+ & 3 & 1.02 \\
\hline High-level contributions $(*)$ & & 42.66 \\
\hline Low-level contributions & & 45.73 \\
\hline \multicolumn{3}{|l|}{ (ii) Affective } \\
\hline A & 4 & 1.37 \\
\hline \multicolumn{3}{|l|}{ (iii) Regulative } \\
\hline RV & 0 & 0.00 \\
\hline RINS & 0 & 0.00 \\
\hline (iv) Rest & & 10.24 \\
\hline AND & 25 & 8.53 \\
\hline GREE & 5 & 1.71 \\
\hline Total & 293 & 100 \\
\hline
\end{tabular}

Note. * indicates high-level cognitive engagement

From Table 4, the cognitive contributions have the highest percentage, with $88.40 \%$, compared to affective $(1.37 \%)$, regulative $(0 \%)$, and rest $(10.24 \%)$. In the cognitive contribution category, there are more low-level contributions $(45.73 \%)$ than high-level contributions $(42.66 \%)$, proving that the messages created by students in the 
discussion forum were with low level cognition and less mental effort, which in turn demonstrates that the quality of learning was relatively poor.

When looking into the cognitive contributions, which consist of high-level contributions (e.g. *CHV 2, *CHG 2, *CI 2, *ACCEPT+ and *NACCEPT+) and lowlevel contributions (e.g. CHV 1, CHVER, CHG 1, CI1, CIT, CIE, ACCEPT- and NACCEPT-), the highest percentage is CI1 (21.84\%), which is giving information without elaboration; followed by ${ }^{*} \mathrm{CHG} 2(18.77 \%)$, which is answering with an explanation using arguments or by asking a counter-question; and *ACCEPT+ $(12.63 \%)$, which is accepting the contribution of another participant with elaboration. In addition, none of the students posted in the forum any message with NACCEPT-, which means not accepting the contribution of another participant without elaboration, showing that they agreed with what their peers posted in the discussion forum. Some of the examples of posts made by students in the forum discussion are shown below:

Student 3: 'For my understanding, most of the computers today can execute only one instruction at a time.' (Code: CI1)

Student 9: 'So the hard disk is important because it stores and provides relatively quick access to a large amount of data on an electromagnetically charged surface or set of surfaces ...' (Code: *CHG2)

Student 11: 'Well, I do agree with him because, nowadays, people are not listening to wise advice, so his action is really helping to actually make the students realise how important life and society than smartphones.' (Code: *ACCEPT+)

Student 20: 'I disagree with his way of rejecting the usage of smartphones because he had to understand that with every evolving thing [that results in] a good change, there's always bad things to accompany it, like yin and yang' (Code: *NACCEPT-)

Student 23: 'Honestly, I disagree with the use of phones in school.' (Code: NACCEPT-)

\subsection{Relationship between students' cognitive engagement level and gender}

There are some factors that might affect the cognitive engagement level of students in an online discussion, one of which might be gender. This statement is supported by Lei, Cui, and Zhou (2018). Thus, it is interesting to investigate this aspect, and this study takes this opportunity to determine the relationship between the students' cognitive engagement level and gender. Table 5 shows the number of students and their cognitive engagement levels based on gender. All four male students possessed a low cognitive engagement level in the discussion forum, while nine female students reached a high cognitive engagement level. This shows that female students made much more mental effort than male students did in the discussion forum.

When examining the relationship between the students' cognitive engagement level and their gender, the result of the Fisher's Exact Test shown in Table 6 indicates that the significant value is .163 , which means there is no statistical significance between gender and cognitive engagement levels. 
Table 5

Number of students with their cognitive engagement level

\begin{tabular}{lcccc}
\hline $\begin{array}{l}\text { Cognitive } \\
\text { Engagement Level }\end{array}$ & Number & $\begin{array}{c}\text { Male } \\
\text { Percentage (\%) }\end{array}$ & Number & Percentage (\%) \\
\hline High & 0 & 0 & 9 & 47.37 \\
HighLow & 0 & 0 & 2 & 10.53 \\
Low & 4 & 100 & 8 & 42.10 \\
Total & 4 & 100 & 19 & 100 \\
\hline
\end{tabular}

Table 6

Chi-Square tests

\begin{tabular}{lcccc}
\hline & Value & df & Asymp. Sig. (2-sided) & Exact Sig. (2-sided) \\
\hline Likelihood Ratio & 5.977 & 2 & .050 & .113 \\
Fisher's Exact Test & 3.733 & & & .163 \\
No of Valid Cases & 23 & & & \\
\hline
\end{tabular}

\subsection{Relationship between students' cognitive engagement level and number of posts}

Another interesting element of this study is that it has not only examined the quality aspect of the discussion forum to determine the students' cognitive engagement level but has also investigated the quantitative aspect, such as the number of posts, which is used to study the relationship between the students' cognitive engagement and their number of posts in the discussion forum. The result also shows the mean and the deviation of the number of posts (11.61 and 4.59 respectively). The students created a total of 267 forum posts. A Spearman's rank-order correlation test was also run to determine the relationship between cognitive engagement level and number of posts, as the results of the ShapiroWilk normality test showed that it is not normally distributed (Table 7).

Table 7

Normality test

\begin{tabular}{lcccccc}
\hline \multirow{2}{*}{$\begin{array}{l}\text { Tests of } \\
\text { Normality }\end{array}$} & \multicolumn{2}{c}{ Kolmogorov-Smirnov } & \multicolumn{3}{c}{ Shapiro-Wilk } \\
& Statistic & df & Sig. & Statistic & df & Sig. \\
\hline cogLevel & .337 & 23 & .000 & .687 & 23 & .000 \\
PostNum & .115 & 23 & .200 & .955 & 23 & .379 \\
\hline
\end{tabular}

The results shown in Table 8 indicate that there was a weak, positive correlation between cognitive engagement level and number of posts, which was not statistically significant with Spearman's correlation coefficient, rs, at 0.12 , and $\mathrm{p}=.957$. 
Table 8

Spearman test

\begin{tabular}{lclcc}
\hline Correlations & PostNum & \multicolumn{1}{c}{ cogLevel } & & \\
\hline Spearman's rho & PostNum & Correlation Coefficient & 1.000 & .012 \\
& & Sig. (2-tailed) &. & .957 \\
& $\mathrm{~N}$ & 23 & 23 \\
& \multirow{2}{*}{ cogLevel } & Correlation Coefficient & .012 & 1.000 \\
& & Sig. (2-tailed) & .957 &. \\
& $\mathrm{~N}$ & 23 & 24 \\
\hline
\end{tabular}

\section{Discussion}

The overall findings indicate that more than half of the students had a low cognitive engagement level. In other words, these students did not extensively use cognitive demand and mental effort when writing their posts in the discussion forum. This finding is consistent with the study conducted by Shukor et al. (2014) in that most of the students had a low cognitive engagement level. This, then, reveals that these students need extra assistance to enhance their cognitive engagement level to improve their learning performance in discussion forums in e-learning. At the same time, such information could also help to inform instructors about whether they need to intervene or offer extra assistance to enhance the students' cognitive engagement in e-learning. On the contrary, $39 \%$ of the students had a high cognitive engagement level, indicating that these students always made a cognitive effort in writing and replying to the posts in the forum. Rotgans and Schmidt (2011) highlighted that those with a higher level of cognitive engagement are the individuals with more knowledge, autonomy, and self-determination. Thus, it can be assumed that these students had mastered much more knowledge and were autonomous learners, which enabled them to have a higher level of cognitive engagement in the discussion forum. For those students who have a low cognitive engagement level, educators should act to determine the alternative methods to enhance their cognitive engagement level. For instance, Valencia-Vallejo, López-Vargas, and SanabriaRodríguez (2019), in their study, proposed that scaffolding can be used to assist students to interact with an e-learning environment, as the findings of the research revealed that scaffolding can help students to enhance their metacognitive ability, academic selfefficacy, and learning performance.

Furthermore, Zhu et al. (2009) reported that students who perform cognitive activities with higher order thinking are expected to yield richer learning experiences and an enhanced performance (Greene et al., 2004). Thus, while it is important for students to achieve higher levels of cognitive engagement, students with low levels are recommended to explore and learn much more knowledge about the given topic in order to become more autonomous and self-determined, which, in turn, can help to enhance the quality of learning in e-learning. This supports the conclusion by Zhu (2006) regarding students' cognitive engagement level in online discussions; Zhu found that the level is correlated to the learning acquired in knowledge and skill acquisition. Therefore, to promote students' cognitive engagement in e-learning discussion forums, instructors are encouraged to provide students with sufficient knowledge and information on the discussion topic, while students themselves should seek sufficient information on the 
given topic so they can put much more effort into constructing the knowledge when writing posts in the discussion forum.

Moreover, from this study's findings, the attribute that contributes most to the cognitive contribution category is CI 1 (21.84\%), which is giving information (an idea or thought) without elaboration. This evidenced that most students prefer to simply give the information without clarification, which might be because their prior knowledge on the given topic was limited or because they tended not to put effort into thinking more deeply to construct the idea when writing the post. This finding is parallel with the previous work conducted by Shukor et al. (2014), who reported that students were likely to copy and paste the information from the internet, thus demonstrating that these students used less cognitive effort to generate the ideas. Thus, educators should be more aware about this problem happened in e-learning.

In addition, students might face the challenge of making high level posts in the discussion forum. However, this situation is fairly common in online learning, as Van der Meijden (2005) also discovered that students found it challenging to achieve a higher level of cognitive interactions, as few of them conducted negotiations or arguments in the discussion. In order to overcome such copy-and-paste problems, which reduce the high levels of student cognitive engagement, instructors should design the discussion topic more carefully, for instance, providing students with topics that require more use of cognitive strategies and higher order thinking, such as "Why?" and "How?". Brown (2010) suggested that the activities that involved more challenging construction and sustained reflection could result in high levels of engagement, while Kew and Tasir (2017) recommended the intervention design for students to enhance their learning performance and overcome the problem of engagement.

Nevertheless, the difference between these high-level and low-level contributions is very slight $(3.06 \%)$. This means that some students were still able to post messages showing high levels of cognitive engagement. Especially, it was found that $* \mathrm{CHG} 2$ involves the second highest cognitive contribution level (18.77\%), revealing that some students had provided the answers to the questions posted by their friends with explanations and elaboration; for example, they used arguments or asked a counterquestion. They had processed the questions and thought deeply before giving their reply in the discussion forum. Additionally, *Accepted+ is the third highest percentage, with $12.63 \%$, which is when the students accepted another participant's contribution with elaboration. These students attempted to search for more evidence and facts to help them decide whether to accept the ideas given by others with concrete reasons for doing so. Through using cognitive strategies, students pay attention to information, store the information in their memories, and use that knowledge to solve problems (Parsons \& Taylor, 2011) and make decisions. Such self-regulated learning helps to enhance students' cognitive engagement levels and would be valuable in helping to create a better intervention to assist students to enhance their cognitive engagement level.

Furthermore, this study also examined the relationship of students' cognitive engagement level with gender and number of posts. The results show that there is no statistical significance between gender and cognitive engagement level. To date, few studies have investigated the relationship between cognitive engagement and gender; thus, our analysis and findings provide a relatively new contribution and a different understanding of the relationship between cognitive engagement and gender in discussion forums. The results prove that gender was not strongly correlated to the students' cognitive engagement. Nonetheless, given that this study was conducted in one subject at 
one institution, future research that replicates and expands on these findings across a variety of disciplines, subjects, and institutions is strongly needed.

In terms of the number of posts, the findings reveal that there was a weak positive correlation between the cognitive engagement level and the number of posts, which was not statistically significant with Spearman's correlation coefficient, rs, at 0.12 , and $\mathrm{p}=$ .957. This shows that the number of posts in the discussion forums was not strongly correlated to the students' cognitive engagement, which is seen as a qualitative aspect of communication. This finding is similar to the outcome of the research conducted by Casimiro (2016), who showed that the number of posts may not always relate to the quality of the students' response. Thus, this finding might indicate that students having high or low numbers of posts in discussion forums does not guarantee that they will achieve a higher level of cognitive engagement. Although MacFadyen and Dawson (2010) reported that the number of posts could be used to predict students' learning achievement, and it is evident that students who interact less are more likely to fail their course (Davies \& Graff, 2005), nonetheless, it is important to note that a high number of posts does not essentially contribute to students' achieving a higher level of cognitive engagement. In addition, it can be stated that the number of postings could not be used as an indicator for the quality of the discussion. Therefore, the findings of this study make another contribution to the field of cognitive engagement research, as there are fewer studies focusing on this aspect.

\section{Conclusion}

In conclusion, online discussion is one of the critical learning activities in e-learning for students to interact with others and express their ideas. These online scripts are the important footprints left by students, as they can be analysed to identify students' cognitive engagement level in discussion forums. This study's findings show that half of the students possessed a low cognitive engagement level in the discussion forums; thus, it highlights that more alternatives need to be investigated to promote and enhance students' cognitive engagement level in discussion forums, which, in turn, will improve the quality of learning.

Furthermore, this study also found that gender and number of posts did not affect the level of students' cognitive engagement in discussion forums. This finding can provide a new idea for educators, namely, that they should not use the number of postings to determine the students' performance in discussion forums. Instead, they should read through the content of the posts. More trainings should be given to instructors to assist them such as workshops (Kew \& Ong, 2019). Lastly, this study's empirical evidence contributes significantly to the body of e-learning on bridging the gap of limited research into students' cognitive engagement levels in discussion forums.

\section{Limitations and future research}

One of this study's limitations is that the number of students involved is not large. To expand this study's generalisability, future studies are required, and a greater scale of investigation with broader populations could be carried out. In addition, the content analysis needs to analyse more details about the students' discussion forums, such as the theme of the posts' content. Moreover, this study also suggests that future research should explore the relationship between cognitive engagement, the number of views, and academic performance. 
Additionally, various types of data generated by students, such as the number of views and the duration of posting on the forum, as well as the length of posts, should be taken into account in future studies so as to provide more insight into students' interaction in forums in e-learning. In addition, different types of analysis methods, such as text mining analysis, can be conducted to compare the difference between content analysis methods and text mining methods to measure cognitive engagement in order to investigate which method is more functional.

\section{Acknowledgements}

The authors would like to thank the Ministry of Higher Education (MOHE) for their support in making this project possible and those who helped in this research. This research was supported by Ministry of Higher Education (MOHE) through Fundamental Research Grant Scheme (FRGS/1/2020/SSI0/UTM/02/11).

\section{Author Statement}

The authors declare that they have no conflict of interest.

\section{ORCID}

Si Na Kew (iD https://orcid.org/0000-0001-6648-6806

Zaidatun Tasir (iD https://orcid.org/0000-0002-6340-3099

\section{References}

Appleton, J. J., Christenson, S. L., Kim, D., \& Reschly, A. L. (2006). Measuring cognitive and psychological engagement: Validation of the student engagement instrument. Journal of School Psychology, 44(5), 427-445.

Archambault, I., Janosz, M., Morizot, J., \& Pagani, L. (2009). Adolescent behavioral, affective, and cognitive engagement in school: Relationship to dropout. Journal of School Health, 79(9), 408-415.

Bai, H. (2003). Social presence and cognitive engagement in online learning environments. In Proceedings of World Conference on E-Learning in Corporate, Government, Healthcare, and Higher Education (pp. 1483-1486).

Bangert, A. W. (2004). The seven principles of good practice: A framework for evaluating on-line teaching. The Internet and Higher Education, 7(3), 217-232.

Boyle, J. T., \& Nicol, D. J. (2003). Using classroom communication systems to support interaction and discussion in large class settings. Research in Learning Technology, $11(3), 43-57$.

Brown, B. (2010). Mathematical literacy: Education for living or examination? Paper presented at AMESSA, Gabarone, Botswana.

Canchola González, J. A., \& Glasserman-Morales, L. D. (2020). Factors that influence learner engagement and completion rate in an XMOOC on energy and sustainability. Knowledge Management \& E-Learning, 12(2),129-146.

Casimiro, L. T. (2016). Cognitive engagement in online intercultural interactions: 
Beyond analytics. International Journal of Information and Education Technology, $6(6), 441-447$.

Chapman, E. (2003). Alternative approaches to assessing student engagement rates. Practical Assessment, Research \& Evaluation, 8: 13.

Cisel, M. (2014). Analyzing completion rates in the first French xMOOC. In Proceedings of the European MOOC Stakeholder Summit (pp. 26-51).

Davies, J., \& Graff, M. (2005). Performance in e-learning: Online participation and student grades. British Journal of Educational Technology, 36(4), 657-663.

De Wever, B., Schellens, T., Valcke, M., \& Van Keer, H. (2006). Content analysis schemes to analyze transcripts of online asynchronous discussion groups: A review. Computers \& Education, 46(1), 6-28. doi: 10.1016/j.compedu.2005.04.005

Gao, F., Zhang, T., \& Franklin, T. (2013). Designing asynchronous online discussion environments: Recent progress and possible future directions. British Journal of Educational Technology, 44(3), 469-483.

Gibbs, R. S., \& Poskitt, J. M. (2010). Student engagement in the middle years of schooling (years 7-10): A literature review. Ministry of Education, New Zealand. Retrieved

from http://citeseerx.ist.psu.edu/viewdoc/download;jsessionid=8F974B72615851E0752A1 511DA3E54D2?doi=10.1.1.475.5394\&rep=rep1\&type $=$ pdf

Goggins, S., \& Xing, W. (2016). Building models explaining student participation behavior in asynchronous online discussion. Computers \& Education, 94, 241-251.

Greene, B. A., Miller, R. B., Crowson, H. M., Duke, B. L., \& Akey, K. L. (2004). Predicting high school students' cognitive engagement and achievement: Contributions of classroom perceptions and motivation. Contemporary Educational Psychology, 29(4), 462-482.

Hammond, M. (2005). A review of recent papers on online discussion in teaching and learning in higher education. Journal of Asynchronous Learning Networks, 9(3), 9-23.

Harris, L. R. (2008). A Phenomenographic investigation of teacher conceptions of student engagement in learning. The Australian Educational Researcher, 35(1), 5779.

Hayati, H, Idrissi, M. K., \& Bennani, S. (2017). Applying text mining to predict learners' cognitive engagement. In Proceedings of the Mediterranean Symposium on Smart City Application (SCAMS).

Helme, S., \& Clarke, D. (2001). Identifying cognitive engagement in the mathematics classroom. Mathematics Education Research Journal, 13(2), 133-153.

Hong, J. C., Tai, K. H., Hwang, M. Y., Kuo, Y. C., \& Chen, J. S. (2017). Internet cognitive failure relevant to users' satisfaction with content and interface design to reflect continuance intention to use a government e-learning system. Computers in Human Behavior, 66, 353-362.

Kew, S. N., \& Ong, C. K. (2019). Introducing a new teaching information system through workshop: Experiences of participants. International Journal of Recent Technology and Engineering, 8(2S9), 770-773

Kew, S. N., Petsangsri, S., \& Tasir, Z. (2020). The relationship between academic performance and motivation level in e-learning among Thailand university students. International Journal of Information and Education Technology, 10(3), 181-185.

Kew, S. N., \& Tasir, Z. (2017). A systematic review of learning analytics intervention contributing to student success in online learning. In Proceedings of the International conference on learning and teaching in computing and engineering (LaTICE) (pp. 62-68).

Kigundu, S. (2014). Engaging e-learning in higher education: Issues and challenges. International Journal of Educational Sciences, 6(1), 125-132. 
Kim, J. (2013). Influence of group size on students' participation in online discussion forums. Computers \& Education, 62, 123-129.

Landis, J. R., \& Koch, G. G. (1977). The measurement of observer agreement for categorical data. Biometrics, 33(1), 159-174.

Lee, L. K., Cheung, S. K. S., \& Kwok, L. F. (2020). Learning analytics: Current trends and innovative practices. Journal of Computers in Education, 7(1), 1-6.

Lei, H., Cui, Y., \& Zhou, W. (2018). Relationships between student engagement and academic achievement: A meta-analysis. Social Behavior and Personality, 46(3), 517-528.

Li, Q., \& Baker, R. (2018). The different relationships between engagement and outcomes across participant subgroups in massive open online courses. Computers \& Education, 127, 41-65.

Lucas, M., Gunawardena, C., \& Moreira, A. (2014). Assessing social construction of knowledge online: A critique of the interaction analysis model. Computers in Human Behavior, 30, 574-582.

Luo, N., Zhang, M., \& Qi, D. (2017). Effects of different interactions on students' sense of community in e-learning environment. Computers \& Education, 115, 153-160. doi: 10.1016/j.compedu.2017.08.006.

Macfadyen, L. P., \& Dawson, S. (2010). Mining LMS data to develop an "early warning system" for educators: A proof of concept. Computers \& Education, 54(2), 588-599.

Mason, L. (2001). Introducing talk and writing for conceptual change: A classroom study. Learning and Instruction, 11(4/5), 305-329.

Mattingly, K. D., Rice, M. C., \& Berge, Z. L. (2012). Learning analytics as a tool for closing the assessment loop in higher education. Knowledge Management \& ELearning, 4(3), 236-247.

Mazzolini, M., \& Maddison, S. (2003). Sage, guide or ghost? The effect of instructor intervention on student participation in online discussion forums. Computers \& Education, 40(3), 237-253.

McLoughlin, C., \& Luca, J. (2000). Cognitive engagement and higher order thinking through computer conferencing: We know why but do we know how? In Proceedings of the 9th Annual Teaching Learning Forum. Perth: Curtin University of Technology.

Moore, R. L., Oliver, K. M., \& Wang, C. (2019). Setting the pace: Examining cognitive processing in MOOC discussion forums with automatic text analysis. Interactive Learning Environments, 27(5/6), 655-669. doi: 10.1080/10494820.2019.1610453

Moreira, P., Cunha, D., \& Inman, R. A. (2020). An integration of multiple student engagement dimensions into a single measure and validity-based studies. Journal of Psychoeducational Assessment, 38(5), 564-580.

Newmann, F. M., Wehlage, G. G., \& Lamborn, S. D. (1992). The significance and sources of student engagement. In F. M. Newmann (Ed.), Student Engagement and Achievement in American Secondary Schools (pp. 11-39). New York, NY: Teachers College Press.

Nor, N. F. M., Razak, N. A., \& Aziz, J. (2010). e-Learning: Analysis of online discussion forums in promoting knowledge construction through collaborative learning. WSEAS Transactions on Communications, 1(9), 53-62.

Oh, E., \& Kim, H. (2016). Understanding cognitive engagement in online discussion: Use of a scaffolded, audio-based argumentation activity. International Review of Research in Open and Distributed Learning, 17(5), 28-48.

Parsons, J., \& Taylor, L. (2011). Improving student engagement. Current Issues in Education, 14(1): 18.

Rotgans, J. I., \& Schmidt, H. G. (2011). Cognitive engagement in the problem-based learning classroom. Advances in Health Sciences Education, 16(4), 465-479.

Salmon, G. (2011). E-moderating: The key to teaching and learning online (3rd ed.). 
New York, NY: Routledge.

Sedaghat, M., Abedin, A., Hejazi, E. \& Hassanabadi, H. (2011). Motivation, cognitive engagement, and academic achievement. Procedia-Social and Behavioral Sciences, $15,2406-2410$.

Shukor, N. A., Tasir, Z., Van der Meijden, H., \& Harun, J. (2014). A predictive model to evaluate students' cognitive engagement in online learning. Procedia-Social and Behavioral Sciences, 116, 4844-4853.

Spanjers, D. M. (2007). Cognitive engagement as a predictor of achievement. Doctoral dissertation, University of Minnesota, USA.

Stoney, C., \& Oliver, R. (1999). Can higher order thinking and cognitive engagement be enhanced with multimedia? Interactive Multimedia Electronic Journal of ComputerEnhanced Learning, 1(2): 7.

Valencia-Vallejo, N., López-Vargas, O., \& Sanabria-Rodríguez, L. (2019). Effect of a metacognitive scaffolding on self-efficacy, metacognition, and achievement in elearning environments. Knowledge Management \& E-Learning, 11(1), 1-19.

Van der Meijden, H. (2005). Knowledge construction through CSCL: Student elaborations in synchronous, asynchronous, and three-dimensional learning environments. Doctoral dissertation, Nijmegen, NL: Radboud University.

Wang, X., Yang, D., Wen, M., Koedinger, K., \& Rosé, C. P. (2015). Investigating how student's cognitive behavior in MOOC discussion forums affect learning gains. Paper presented at the International Conference on Educational Data Mining (EDM).

West, D., Tasir, Z., Luzeckyj, A., Kew, S. N., Toohey, D., Abdullah, Z., ... Price, R. (2018). Learning analytics experience among academics in Australia and Malaysia: A comparison. Australasian Journal of Educational Technology, 34(3), 122-139.

Wysocki, C. D. (2007). A study of cognitive engagement in online learning. Doctoral dissertation, Washington State University, USA.

Yin, C., \& Hwang, G. J. (2018). Roles and strategies of learning analytics in the epublication era. Knowledge Management \& E-Learning, 10(4), 455-468.

Zhu, E. (2006). Interaction and cognitive engagement: An analysis of four asynchronous online discussions. Instructional Science, 34(6), 451-480.

Zhu, X. H., Chen, A., Ennis, C., Sun, H. C., Hopple, C., Bonello, M., ... Kim, S. (2009). Situational interest, cognitive engagement, and achievement in physical education. Contemporary Educational Psychology, 34(3), 221-229.

Zyngier, D. (2007). Listening to teachers-listening to students: Substantive conversations about resistance, empowerment and engagement. Teachers and Teaching: Theory and Practice, 13(4), 327-347. 